\title{
Biomaterials
}

\section{Study of the thermal stability and enzymatic activity of an immobilised enzymatic system for the bilirubin oxidation}

\author{
M.M. Vidala ${ }^{\mathrm{a}}$, M.H. Gil ${ }^{\mathrm{a}, *}$, I. Delgadillo ${ }^{\mathrm{b}}$, J. Alonso $^{\mathrm{c}}$ \\ ${ }^{a}$ Departamento de Engenharia Quimica, Universidade de Coimbra, Faculdade de Ciencias e Technologia, 3000 Coimbra, Portugal \\ ${ }^{\mathrm{b}}$ Departamento Química, Universidade de Aveiro, 3830 Aveiro, Portugal \\ ${ }^{\mathrm{c}}$ Grupo de Sensores y Biosensores, Departamento de Química, UAB, 08193 Bellaterra, Spain
}

Received 26 February 1998; accepted 10 November 1998

\begin{abstract}
In this work, we have studied the immobilisation of the haemoglobin/glucose oxidase coupled enzymatic system in poly(vinyl alcohol) membranes. These are to be used as a reagent phase either in the development of an optical sensor or as an efficient bilirubin (BR) removal reactor. Poly(vinyl alcohol) (PVA) was chosen as the support for this purpose, due to its good biocompatibility, hydrophilicity and non-thrombogenic effects. A hydrogel containing the enzymatic system, consisting of PVA crosslinked with glutaraldehyde, was prepared and characterised by DSC, enzyme activity measurements and release tests. Investigating protein conformational changes as a function of temperature and the enzymatic system activity we have found that, in spite of the destabilizing effect of the glutaraldehyde in the acidic medium, the PVA insolubilisation conditions seem do not perturb either the conformation of the 'native state' nor the enzymatic system activity. Moreover, it was found that PVA/glutaraldehyde membranes offer a simple way to hold enzymatic system, with the possibility of controlling the conditions to obtain either the effective prevention of leaching of the entrapped proteins or the in situ delivery of the haemoglobin. (C) 1999 Elsevier Science Ltd. All rights reserved
\end{abstract}

Keywords: Bilirubin; Haemoglobin; Glucose oxidase; Poly(vinyl alcohol); Differential scanning calorimetry (DSC)

\section{Introduction}

Bilirubin is a metabolite of blood haem breakdown and is potentially toxic to plasma membranes. High levels of BR is of much concern in new-born babies (physiologic jaundice) while in adults, quantitative detection of abnormal levels provides accurate information about troubles in BR metabolism. Bilirubin (BR) can be determined in several ways, although the most common method still involves the van den Bergh reaction, employing diazotized sulphanilic acid to form red azodipyrroles $[1,2]$.

Many efforts have been made to obtain more accurate and simple routine analytical methods [3-9]. Special attention has been given to the application of the enzymes. In the literature different enzymatic systems have been suggested: glucose oxidase and peroxidase $[10,11]$, bilirubin oxidase alone $[8,9,12-15]$ or together with peroxidase and glucose oxidase $[16,17]$, to enhance BR

*Corresponding author. Fax: 0035139 841138; e-mail: hgil@eq.uc.pt degradation effect. Some of these enzymatic methods are also suitable for BR removal from blood where the enzyme specificity is very important, due to the necessity to avoid the elimination of other essential blood components, thus minimizing the volume of the blood in the extracorporeal circuit $[12,16]$.

In a previous work, we have proposed an inexpensive and accessible coupled enzymatic system for BR oxidation [18]. This involves haemoglobin $(\mathrm{Hb})$ and glucose oxidase (GOX): $\mathrm{Hb}$ and hydrogen peroxide oxidise $\mathrm{BR}$ to a colourless compound, with the hydrogen peroxide being produced in situ by the well-established glucose oxidase catalysed reaction.

Glucose $\stackrel{\text { GOX }}{\longrightarrow} \mathrm{H}_{2} \mathrm{O}_{2}$

Bilirubin $\stackrel{\text { Haemoglobin } / \mathrm{H}_{2} \mathrm{O}_{2}}{\longrightarrow}$ Biliverdin

(Yellow) (Colourless)

The work presented here reports the development of a PVA membrane containing the $\mathrm{Hb} / \mathrm{GOX}$ enzymatic system, which works as the biochemical recognition 
system. The membrane was obtained by crosslinking PVA and the enzymatic system with glutaraldehyde consisting in a quite advantageous procedure due to its simplicity and ability to hold high matrix loads. In this stage of our work, well characterised membranes of small dimensions were prepared and tested. The effect of the crosslinking conditions on the protein structure and on the enzyme activity were evaluated by DSC. In this way, we investigated the protein conformational changes as a function of temperature in the presence of the glutaraldehyde. The aim of our investigations consisted in following any profile changes on the proteins thermal denaturation considering the native enzyme profile as a reference. In the end, we tried to relate the observed conformational changes with the enzyme activity.

\section{Experimental part}

\subsection{Reagents}

Poly(vinyl alcohol) (molecular weight of $14000,98 \%$ hydrolysed) was obtained from $\mathrm{BDH}$, Chemicals Ltd, Poole, England. Bovine haemoglobin $(\mathrm{Hb})$, glucose oxidase (GOX EC 1.1.3.4) from Aspergillus niger type VII, bovine serum albumin (BSA) and bilirubin (BR) from bovine gall stones were obtained from Sigma Chemical Co., sodium dodecyl sulphate (SDS) and tris(hydroxylmethyl)aminomethane were purchased from Aldrich Chemical Company Inc. (England) and $\mathrm{HCl}(37 \%)$ and glutaraldehyde (25\%) from Merck (Darmstadt, Germany).

\subsection{Preparation of the membranes}

Membranes were prepared: with PVA (procedure A) and without PVA (procedure B). The solutions obtained were cast on a glass plate $(2 \mathrm{~cm} \times 2 \mathrm{~cm})$ and the solvent evaporated for $24 \mathrm{~h}$ at $25^{\circ} \mathrm{C}$. PVA solution was prepared by dissolving PVA $(10 \% \mathrm{w} / \mathrm{w})$ in water at $80^{\circ} \mathrm{C}$ until complete solubilization. Glutaraldehyde standard solution was prepared by diluting to $50 \mathrm{~cm}^{3}$, with distilled water, $3 \mathrm{~cm}^{3}$ of commercial glutaraldehyde solution $(25 \%)$.

\subsubsection{Procedure A-PVA membranes}

To $4 \mathrm{~cm}^{3}$ of the aqueous PVA solution $(10 \% \mathrm{w} / \mathrm{w})$, $0.3 \mathrm{~cm}^{3}$ of $0.5 \mathrm{M} \mathrm{HCl}$ and $2.5 \mathrm{~cm}^{3}$ of the glutaraldehyde standard solution were added. Then, $0.68 \mathrm{~cm}^{3}$ of this PVA solution were added to the proteins $(\mathrm{Hb}$ or $\mathrm{Hb}$ and GOX), previously solubilised in $0.32 \mathrm{~cm}^{3}$ of distilled water.

\subsubsection{Procedure B-protein/glutaraldehyde mixtures}

$0.3 \mathrm{~cm}^{3}$ of water and $2.5 \mathrm{~cm}^{3}$ of the glutaraldehyde standard solution were added to $4 \mathrm{~cm}^{3}$ of distilled water. $0.68 \mathrm{~cm}^{3}$ of this aqueous glutaraldehyde solution was added to solution of the proteins $(\mathrm{Hb}$ or $\mathrm{Hb}$ and GOX) in distilled water $\left(0.32 \mathrm{~cm}^{3}\right)$. A similar procedure was followed to study the influence of the acid medium adding $0.3 \mathrm{~cm}^{3}$ of $0.5 \mathrm{M} \mathrm{HCl}$ instead of the $0.3 \mathrm{~cm}^{3}$ of water.

\subsection{Enzymatic assay}

Figure 1 shows, schematically, the experimental procedure, used to assay the enzymatic activity of the PVA membranes (procedure A). For the enzymatic assay, 100 and $20 \mu \mathrm{M} \mathrm{BR/albumin} \mathrm{standard} \mathrm{solutions} \mathrm{were} \mathrm{pre-}$ pared as previously described [18]. A $0.1 \mathrm{~m}$ Tris buffer solution $(\mathrm{pH}=8)$ was prepared containing SDS (denoted Tris/SDS). According to the optimum level established by Bergmeyer, $5 \mathrm{~mm}$ SDS concentration was chosen to cleave BR/albumin association and assure a quick oxidation of the BR $[1,18] .0 .05 \mathrm{~m}$ glucose and $0.1 \mathrm{mg} / \mathrm{cm}^{3}$ GOX solutions were prepared with this Tris/SDS buffer. For the activity determination of the membranes containing $\mathrm{Hb}$ and GOX, BR solutions were prepared by mixing $1 \mathrm{~cm}^{3}$ of the $100 \mu \mathrm{M} \mathrm{BR} /$ albumin standard solution with $1.5 \mathrm{~cm}^{3}$ of the Tris/SDS buffer and $0.5 \mathrm{~cm}^{3}$ of the glucose solution. For the activity determination of membranes containing only $\mathrm{Hb}$, the BR solutions contained not only $1 \mathrm{~cm}^{3}$ of a $20 \mu \mathrm{M}$ BR standard solution and $1 \mathrm{~cm}^{3}$ of Tris/SDS buffer, but also $0.5 \mathrm{~cm}^{3}$ of glucose $0.05 \mathrm{M}$ and $0.5 \mathrm{~cm}^{3}$ of GOX $0.1 \mathrm{mg} / \mathrm{cm}^{3}$. The absorbance values at $450 \mathrm{~nm}$, of these BR sample solutions, were determined. Then the membranes were introduced in the vessels containing the BR solutions. The BR oxidation was then carried out for $15 \mathrm{~min}$ with stirring. The reaction was stopped with the membrane remotion. Absorbance values at $450 \mathrm{~nm}$ of the BR sample solution was determined once again. Both absorbance values at $450 \mathrm{~nm}$, before and after contact with the membrane were compared (spectrum $a$ and $b$, respectively).

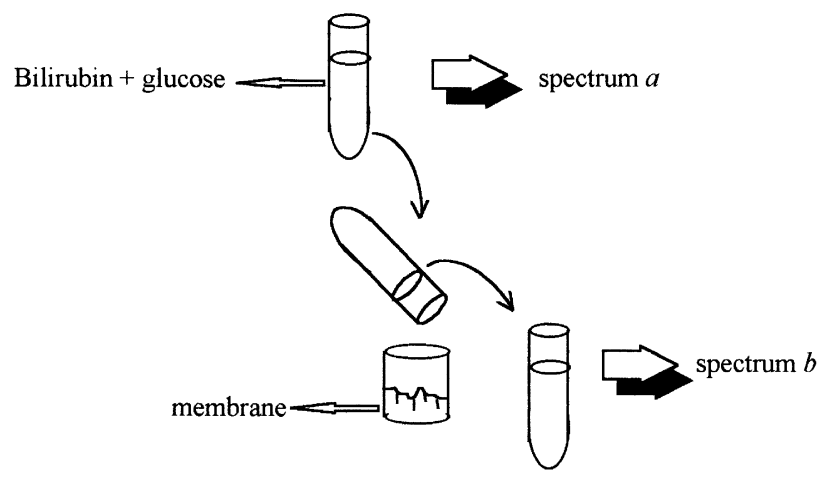

Fig. 1. Schematic representation of the experimental procedure for the activity assay of the immobilised $\mathrm{Hb} / \mathrm{GOX}$ system. 


\subsection{DSC measurements}

Differential scanning calorimetry (DSC) thermograms were obtained using a Polymer Laboratories DSC unit. The samples, consisting of the proteins/glutaraldehyde mixtures (procedure $\mathrm{B}$ ) were dried to constant weight in vacuum in the presence of $\mathrm{P}_{2} \mathrm{O}_{5}$ at $25^{\circ} \mathrm{C} .2-5 \mathrm{mg}$ samples of these membranes were analysed at a $10^{\circ} \mathrm{C} / \mathrm{min}$ heating rate, under a nitrogen atmosphere.

\section{Results and discussion}

The enzymatic system was immobilised by occlusion in a PVA gel made by adding glutaraldehyde to a PVA solution. The reaction between hydroxyl and aldehyde groups is acid catalysed, leading to an acetal linkage [18, 19]. The influence of $\mathrm{pH}$ and glutaraldehyde on the thermal stability of the proteins ( $\mathrm{Hb}$ and GOX separately) was determined.

\subsection{Haemoglobin thermal stability}

Figure 2 shows the DSC thermograms for $\mathrm{Hb}$ thermal denaturation. Curve A corresponds to the powdered sample, where the symbols $T_{\mathrm{m}}$ and $T_{\mathrm{d}}$ denote the melting and the decomposition temperature of the native protein. The melting or the denaturation of the protein process leads to an increase of the heat capacity. The maximum limit is reached, in this case, at about $120^{\circ} \mathrm{C}$, while chemical decomposition occurs around $210^{\circ} \mathrm{C}$, with some loss of heat capacity.

In the same figure, thermograms $B$ and $C$ show the influence of glutaraldehyde in the presence and in the absence of the acid on the melting and decomposition processes. The $\mathrm{Hb} / \mathrm{glutaraldehyde}$ ratio is similar to those at PVA membranes.

Comparing $T_{\mathrm{m}}$ values in the thermograms $\mathrm{B}$ and $\mathrm{C}$ with the $T_{\mathrm{m}}$ value in the thermogram A, we can see that the presence of the glutaraldehyde affects the $T_{\mathrm{m}}$ only when the crosslinking reaction occurs in the acidic medium. In curve $\mathrm{C}$, the slight decrease of the $T_{\mathrm{m}}$ value, suggests that, under these conditions, the thermal stability of the protein decreases [20]. However, the three $\mathrm{Hb}$ denaturation processes are quite similar and the value of the width at half-peak height, $\Delta T_{1 / 2}$, remains constant and equal to the value obtained for the native protein. This means that the reaction conditions, for the PVA insolubilization, does not significantly perturb the conformation of the 'native' state [21].

The only thermodynamic parameter which seems to be affected significantly by crosslinking, is the thermal decomposition of the protein, which disappears in both $\mathrm{Hb}$ /glutaraldehyde mixtures (Fig. 2). This stabilisation of the protein molecules to thermal decomposition can be assigned to the well-known phenomenon described in 1948 by Ferry due to the heat-induced association of the denaturated molecules which, based on the DSC data is promoted by the addition of the glutaraldehyde [22].

\subsection{Glucose oxidase thermal stability}

The effect of the glutaraldehyde on the GOX conformational change, as a function of temperature, was also investigated. Figures 3 and 4 show the relevant thermograms. In both figures, curve A represents the thermogram of the GOX powdered sample, where the three transitions are identified according to Kennamer [20]: at

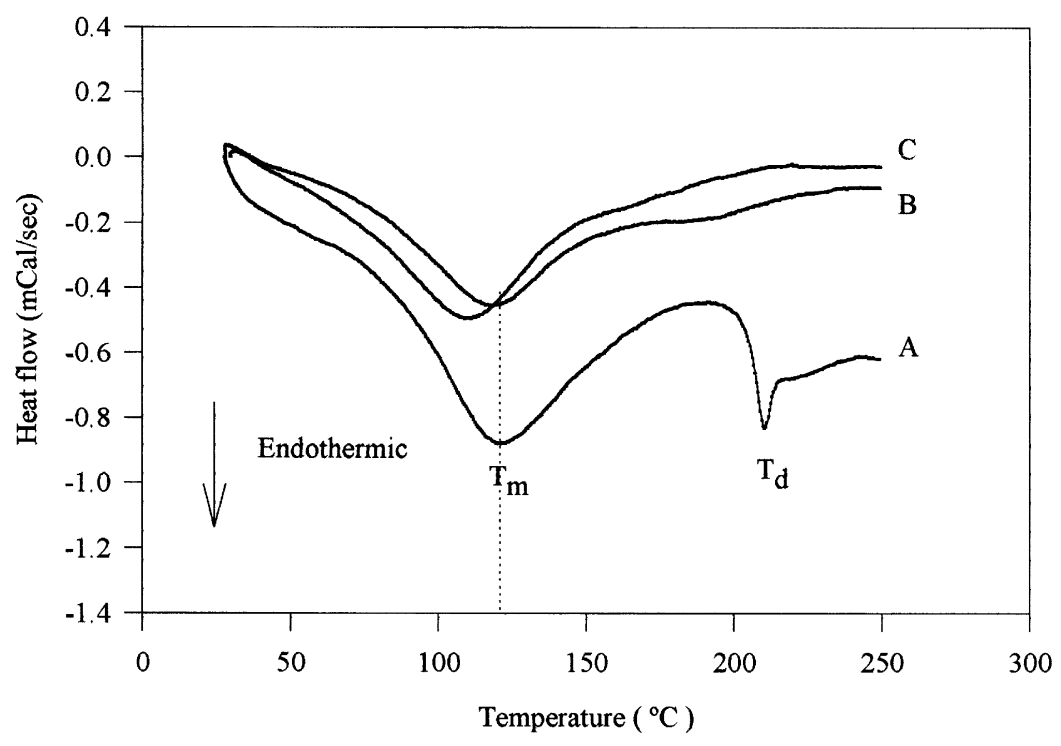

Fig. 2. A, Thermogram of haemoglobin-powdered sample (4.2 mg); thermograms of the $\mathrm{Hb} /$ glutaraldehyde mixtures, in accordance with procedure B. B, without $\mathrm{HCl}(2.4 \mathrm{mg})$; , with $\mathrm{HCl}(2.0 \mathrm{mg})$. 


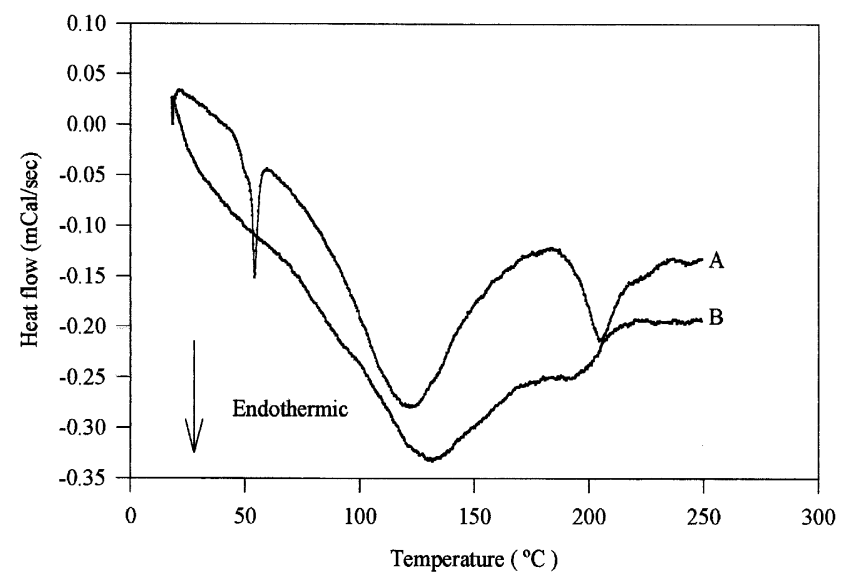

Fig. 3. Thermograms of different GOX samples: A, GOX powdered sample ( $2 \mathrm{mg})$; B, GOX/glutaraldehyde mixture $(2.1 \mathrm{mg})$.

$54^{\circ} \mathrm{C}$, the glass transition $T_{\mathrm{g}}$, followed by the first-order transition, corresponding to the denaturation process, and the last transition, at $205^{\circ} \mathrm{C}$, corresponding to protein decomposition.

Curves B, in both figures, show the thermograms of a GOX/glutaraldehyde mixture, obtained by mixing the enzyme and the glutaraldehyde at the same ratio as in a normal PVA membrane (see Experimental Part-procedure B). In Fig. 3, curve B is related to the GOX/ glutaraldehyde sample prepared without $\mathrm{HCl}$, while in Fig. 4, curve B is related to the GOX/glutaraldehyde sample prepared in the acidic medium. In both thermograms B, the disappearance of the peak around $200^{\circ} \mathrm{C}$, suggests that there is a stabilisation of the GOX, and no thermal degradation occurs. Probably, as suggested by Ferry [22], the presence of the glutaraldehyde provides a way of gellification of the proteins to stabilise them for higher temperatures. In Fig. 3, curve B, the glass transition disappears. It is also evident that there is an alteration on the enthalpy change of the denaturation process. Considering the increase in the $\Delta T_{1 / 2}$ value, it is suggested that, in the presence of glutaraldehyde, the cooperative degree of the GOX denaturation process decreases, in agreement with a lower conformational thermostability.

On the other hand, in the acidic medium (curve B, Fig. 4) the glass transition, of the GOX/glutaraldehyde mixture, does not disappear, while decreases both in $T_{\mathrm{g}}$ and $T_{\mathrm{m}}$ values are observed. Therefore, at lower $\mathrm{pH}$ values, although the enzyme becomes thermally unstable at a lower temperature, according to thermodynamic parameters such as enthalpy change and the $\Delta T_{1 / 2}$ value, the GOX is more thermostable. The enthalpy change and the same degree of cooperativity as the native enzyme suggest that, in the presence of the glutaraldehyde and for low $\mathrm{pH}$ values, GOX assumes a conformation, identical to that of the pure enzyme.

\subsection{Catalytic activity measurements}

In the previous sections, we have shown how glutaraldehyde alone or in the presence of $\mathrm{HCl}$ can influence thermal stability and conformation of the proteins. Although the glutaraldehyde/acid medium does not seem to interfere with the protein conformation, here, we report the studies to investigate if there is any undesirable effects on $\mathrm{Hb}$ and GOX functional properties, after they were entrapped in the PVA membrane crosslinked with glutaraldehyde. The catalytic activity of four enzymatic systems (membranes 1-4), whose composition is described in Table 1, were tested by evaluating their capacity to oxidise BR to biliverdin.

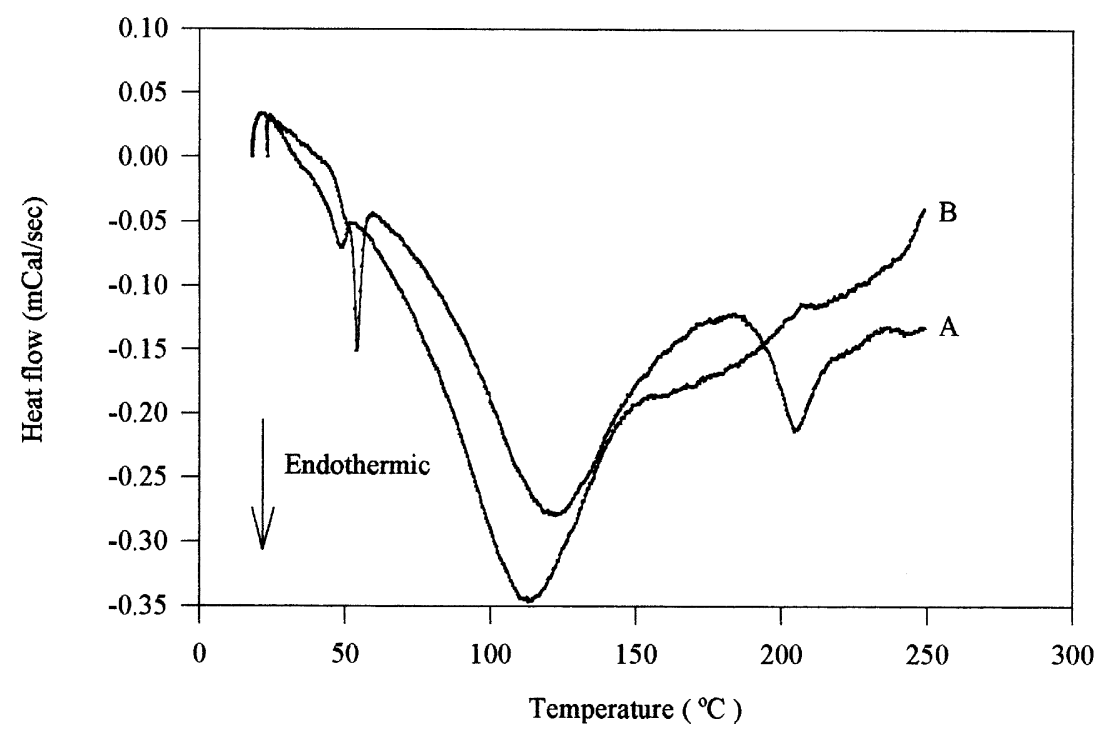

Fig. 4. Thermograms of different GOX samples: A, GOX powdered sample (2 mg); B, GOX/glutaraldehyde mixture adding $\mathrm{HCl}(2.2 \mathrm{mg})$. 
Table 1

Composition of the 1-4 PVA membranes prepared with different $\mathrm{Hb}$ and $\mathrm{GOX}$ concentrations. PVA $4 \%, \mathrm{HCl} 0.015 \mathrm{M}$ and glutaraldehyde $0.4 \%(\mathrm{w} / \mathrm{v})$

\begin{tabular}{llll}
\hline Material & Hb (\%) & GOX (\%) & $\begin{array}{l}\text { GOX (\%) in the } \\
\text { reaction medium }\end{array}$ \\
\hline 1 & 2.5 & 2.5 & - \\
2 & 0.5 & 0.5 & - \\
3 & 5.0 & - & 1.7 \\
4 & 0.5 & - & 1.7 \\
\hline
\end{tabular}

Comparing the results in the Fig. 5a and b, the decrease of the absorbance at $450 \mathrm{~nm}$ (the rate of the oxidation) is different for the membranes 1 and 2. From a brief study of reproducibility for the membrane 1 (membrane prepared with the highest enzymatic system concentration), a standard deviation corresponding to a $25 \%$ variation from the respective mean has been obtained. This lack of reproducibility could be associated with the $\mathrm{Hb}$ release. Due to these results the system PVA/Hb was characterised by evaluating the $\mathrm{Hb}$ release behaviour.

\subsection{Release tests}

In order to optimise the system, by decreasing the $\mathrm{Hb}$ releasing, new membranes without GOX were prepared (membranes 3 and 4). Their behaviour in contact with a solution containing GOX and BR was studied using the same batch method (see Fig. 1).

In Fig. 6 , spectrum $b$ is related to a $7 \mu \mathrm{M}$ BR sample solution after the contact with the membrane 3 , containing a $\mathrm{Hb}$ amount corresponding to the sum of $\mathrm{Hb}$ and GOX amount contained in membrane $1(5.0 \%)$. This spectrum shows a peak at $420 \mathrm{~nm}$, within the Soret region $(400-440 \mathrm{~nm})$. In the same figure, for the same 15 min contact time, spectrum $c$ corresponds to a sample, where the $20 \mu \mathrm{M}$ BR standard was replaced by an equal volume of Tris buffer. The absorbance peak at $420 \mathrm{~nm}$ is still observed, and can be assigned to haemoglobin released into the solution which confirm that in these conditions $\mathrm{Hb}$ is leaked. The large overlap between $\mathrm{Hb}$ and $\mathrm{BR}$ absorption bands, introduces a systematic error for quantitative determination of $\mathrm{BR}\left(\Delta_{1}\right.$ instead of $\left.\Delta_{1}+\Delta_{2}\right)$. Therefore, a modified spectrophotometric procedure for BR determination should involve subtraction of the $\mathrm{Hb}$ absorbance $\left(\Delta_{2}\right)$, from spectrum $b$. This operation leads to a new spectrum ( $d$-dashed line) which allows the estimation of the real BR enzymatic degradation $\left(\Delta_{1}+\Delta_{2}\right)$.

With membrane 4, prepared with less $\mathrm{Hb}$ amount $(0.5 \%)$, in a similar way, spectra $a-d$ are represented in Fig. 7. Spectra $b$ and $c$, for the samples, with and without BR after contact with the membrane, do not show the characteristic $\mathrm{Hb}$ band. The BR absorption band does
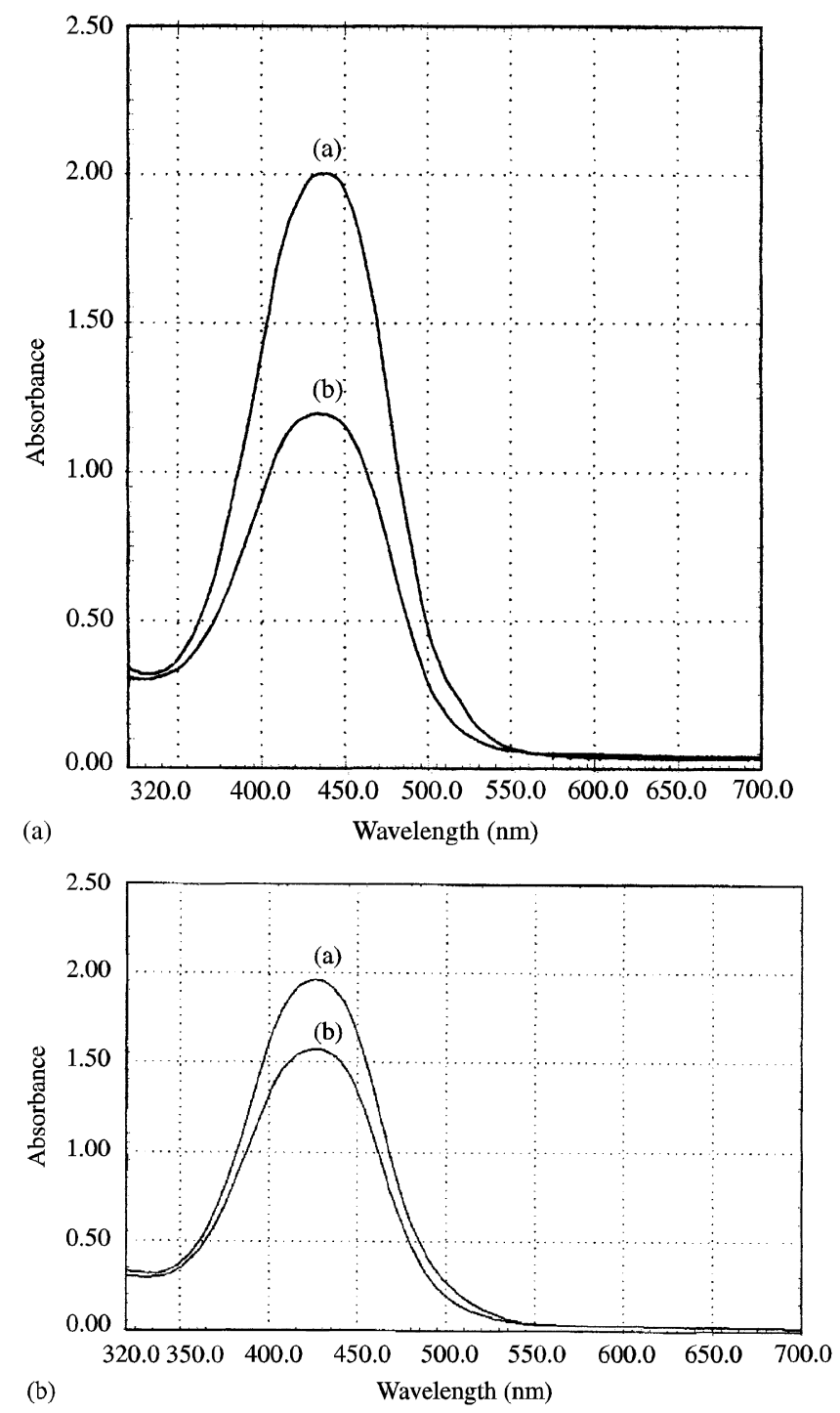

Fig. 5. Oxidation of a $30 \mu \mathrm{M}$ BR solution, for a 15 min contact, with the enzymatic system immobilised in a poly(vinyl alcohol) membrane (a) membrane 1, Hb 2.5 and GOX 2.5\%; (b) membrane 2, Hb $0.5 \%$ and GOX $0.5 \%$ (the assay procedures are indicated in Fig. 1).

not overlap and the decrease of the absorbance, at $450 \mathrm{~nm}$, between spectrum $c$ and $b$ is close to that due to the BR oxidation $\left(\Delta_{1}+\Delta_{2} \approx \Delta_{1}\right)$. This means that, we have found a way to prevent $\mathrm{Hb}$ leakage when using the PVA/glutaraldehyde membrane to immobilise the proteins. This consisted in reducing the initial $\mathrm{Hb}$ amount entrapped within the hydrogel.

In addition, from the results obtained (see absorbance difference at $450 \mathrm{~nm}$ between spectra $a$ and $d$ in Figs. 6 and 7), we also can conclude that the absorbance decrease is similar for both membranes 3 and 4 . These PVA membranes can therefore be designed to degrade BR, either by releasing $\mathrm{Hb}$ (for solutions containing GOX) or by not releasing the $\mathrm{Hb}$. If the $\mathrm{Hb}$ is not released, $\mathrm{BR}$ is degraded after its ingress, and $\mathrm{H}_{2} \mathrm{O}_{2}$ obtained from 


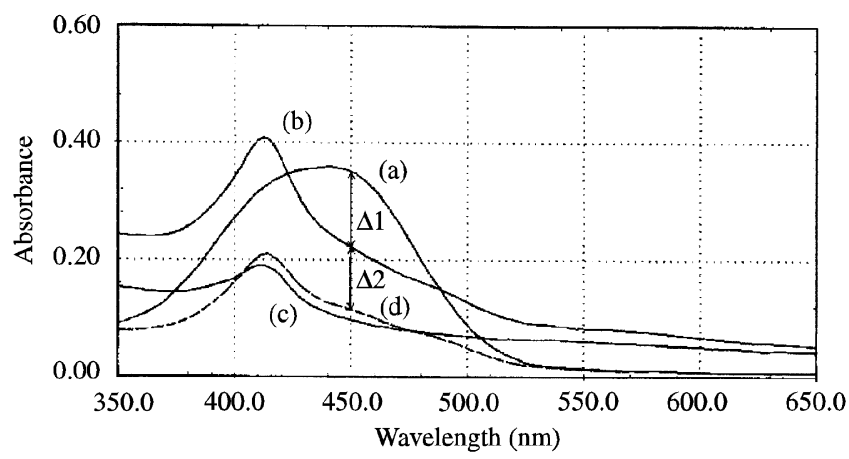

Fig. 6. Spectrophotometric absorption curves for membrane 3: a, $7 \mu \mathrm{M}$ BR sample; b, the same $7 \mu \mathrm{M}$ BR sample, for a 15 min contact; c, sample solution with no BR, for a 15 min contact; $\mathrm{d}$, spectrum $b$ with $\mathrm{Hb}$ absorbance subtracted.

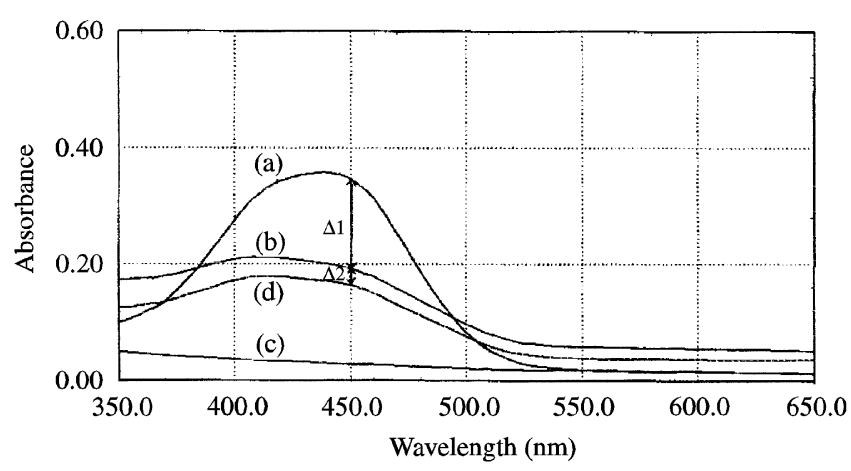

Fig. 7. Spectrophotometric absorption curves for membrane 4: a, $7 \mu \mathrm{M}$ BR sample; b, the same $7 \mu \mathrm{M}$ BR sample, for a 15 min contact; c, sample solution with no BR, for a 15 min contact; $\mathrm{d}$, spectrum $b$ with $\mathrm{Hb}$ absorbance subtracted.

solution, in the membrane (membrane 4). If $\mathrm{Hb}$ is released both phenomena can occur, i.e. BR is degraded inside and outside of the membrane. In both cases, the percentage of degradation is the same, which, however, could be due to the substrate concentration becoming the limiting factor. In fact when BR concentration is increased as it was for the enzymatic assay of membranes 1 and 2, membrane 1, containing higher amount of the enzymatic system, appears to be much more efficient than membrane 2. However, in this case, GOX could become the limiting factor of the system.

The achievements reported in the previous discussion are of especial importance if we consider to what these membranes are made for. Depending on the $\mathrm{Hb}$ amount used on the membrane preparation, it is possible to prepare, on the one hand, polymeric systems providing the effective prevention of leaching of the entrapped proteins, which is very convenient to avoid the blood contamination when used as a reactor for the detoxification of BR. On the other hand, it allows to prepare polymeric systems for the in situ delivery of the haemoglobin as self-contained biosensors for in vivo monitor- ing of BR concentration in mediums, such as the gastric juice, where the continuous $\mathrm{Hb}$ supply is an essential demanding factor $[23,24]$.

\section{Conclusions}

The Hb/GOX coupled system was immobilised by occlusion in a PVA gel, which will be used as a reagent phase in the development of an optical sensor or an efficient BR removal reactor. We have used DSC for investigating protein conformational changes as a function of temperature, under the PVA gelling reaction conditions and simultaneously, catalytic activity measurements and release tests were performed.

From our results we can conclude that:

1. Both $\mathrm{Hb} /$ glutaraldehyde/acid and GOX/glutaraldehyde/acid become thermally instable at lower temperatures, though conformational changes of both proteins are identical to those of the native state.

2. We were successful in maintaining the catalytic activity of the enzymatic system within the PVA hydrogel, though there is also the possibility of using these hydrogels to release $\mathrm{Hb}$.

Based on this work, we can conclude that the development of membranes with controlled permeability is fundamental for further development of a biosensor. As referred to earlier [17] the main factors that influence the permeability properties are the enzymatic system/polymer ratio (loading) and the crosslinking density.

\section{Acknowledgements}

We gratefully acknowledge the grant from JNICT (Portugal).

\section{References}

[1] Bergmeyer HU. Methods of enzymatic analysis, 3rd edn, vol. 8. Weinheim (FRG): VCH, 1985:591-8.

[2] Suzuki Y. Determination of total bilirubin in serum by a color reaction using p-dimethylaminobenzaldehyde. Anal Sci 1997; 13(2):291-4.

[3] Wang J, Ozsoz M. A polishable amperometric biosensor for bilirubin. Electroanalysis 1990;2:647-50.

[4] Aiken JH, Huie CW. Detection of bilirubin using surfactant fluorescence enhancement and visible laser fluorometry. Anal Lett 1991;24(1):167-80.

[5] Wu N, Horvath WJ, Huie CW. Light emission from bilirubin using the peroxyoxalate chemiluminescence reaction. Anal Chim Acta 1992;269:99-107.

[6] Bae ZU, Lee HL, Park TM, Seo ML. Amperometric determination of bilirubin with flow injection analysis system. Anal Lett 1995;28(10):1775-83.

[7] Palilis LP, Calokerinos AC, Grekas N. Chemiluminescence arising from the oxidation of bilirubin in aqueous media. Anal Chim Acta 1996;333(3):267-75. 
[8] Li XP, Fortuney A, Guilbault GG, Suleiman AA. Determination of bilirubin by fiberoptic biosensor. Anal Lett 1996; 29(2):171-80.

[9] Li XP, Rosenzweig Z. A fiber optic sensor for rapid analysis of bilirubin in serum. Anal Chim Acta 1997;353(2-3):263-73.

[10] Nakamura H, Lee Y. Microdetermination of unbound bilirubin in icteric newborn sera: an enzymatic method employing peroxidase and glucose oxidase. Clin Chim Acta 1977; 79:411-7.

[11] Renneberg R, Pfeiffer D, Scheller F. Enzyme sequence and competition electrodes based on immobilized glucose oxidase, peroxidase and catalase. Anal Chim Acta 1982;134:359-64.

[12] Sung C, Lavin A, Klibanov AM, Langer R. An immobilized enzyme reactor for the detoxification of bilirubin. Biotechnol Bioengng 1986;28:1531-9.

[13] Mullon CJP, Langer R. Determination of conjugated and total bilirubin in serum of neonates, with use of bilirubin oxidase. Clin Chem 1987;33/10:1822-5.

[14] Kurosaka K, Senba S, Tsubota H, Kondo H. A new enzymatic assay for selectively measuring conjugated bilirubin concentration in serum with use of bilirubin oxidase. Clin Chim Acta 1998;269(2):125-36.

[15] Fortuney A, Guibault GG. Enzyme electrode for the determination of bilirubin. Electroanal 1996;8(3):229-32.
[16] Daka NJ, Sipephia R, Chang TMS. Enhanced oxidation of bilirubin by an immobilized tri-enzyme system of glucose oxidase, bilirubin oxidase, peroxidase and catalase. Anal Chim Acta 1982;134:359-64.

[17] Guo YZ, Dong SJ. Organic phase enzyme electrodes based on organohydrogel. Anal Chem 1997;69(10):1904-8.

[18] Vidal MM, Delgadillo I, Gil MH, Alonso JC. Study of an enzyme coupled system for the development of fibre optical bilirubin sensors. Biosens Bioelectr 1996;11(4):347-54.

[19] Paul D. Polymer hollow fiber membranes for removal of toxic substances from blood. Progr Polym Sci 1989;14:597-627.

[20] Kennamer JE, Usmani AM. DSC analysis of select diagnostic enzymes. J Appl Polym Sci 1991;42:3073-4.

[21] Relkin P. Differential scanning calorimetry: a useful tool for studying protein denaturation. Thermochim Acta 1994;246:371-86.

[22] Ferry JD. Protein gels. Adv Protein Chem 1948;4:1.

[23] Baldini F, Falciai R, Bechi P, Cosi F, Bini A, Milanesi F. A portable and very inexpensive optical-fiber sensor for entero-gastric reflux detection. SPIE vol. 1510 Chemical and Medical Sensors 1991:58-62.

[24] Kauer WK, Peters JH, DeMeester TR, Feussner H, Ireland AP, Stein HJ, Siewert RJ. Composition and concentration of bile acid reflux into the esophagus of patients with gastroesophageal reflux disease. Surgery 1997;122(5):874-81. 